\title{
Overcoming poor in vitro nuclear maturation and developmental competence of domestic cat oocytes during the non-breeding season
}

\author{
P. Comizzoli, D. E. Wildt and B. S. Pukazhenthi \\ Department of Reproductive Sciences, Smithsonian's National Zoological Park, 3001 Connecticut \\ Avenue NW, Washington, District of Columbia 20008-2598, USA
}

The domestic cat experiences circannual variations in ovarian activity and intrafollicular oocyte quality. One result is poor nuclear and cytoplasmic maturation during in vitro maturation (IVM) conducted during the annual non-breeding season (July through November). In an attempt to overcome this seasonal phenomenon immature oocytes were collected from July through November and cultured in a conventional IVM medium (IVM1) or in IVM1 supplemented with different FSH concentrations and antioxidant (ascorbic acid or cysteine). Nuclear status of oocytes was assessed after IVM or IVF. Embryo stage and blastocyst quality were evaluated after 7 days of in vitro culture. Although the addition of antioxidant alone had no effect, the presence of $10 \mu \mathrm{g} \mathrm{FSH} \mathrm{ml} \mathrm{I}^{-1}$ improved nuclear maturation $(75.4 \pm 4.1 \%$ versus $48.7 \pm 8.8 \%$ in IVM1; $P<0.05)$ and fertilization success $(47.9 \pm 3.2 \%$ versus $35.0 \pm 5.1 \%$ in IVM1; $P<0.05)$. Furthermore, developmental competence of fertilized oocytes was enhanced $(P<0.05)$ only in the presence of ascorbic acid $(30.6 \pm 6.7 \%)$ or cysteine $(33.6 \pm 5.1 \%)$ compared with IVM1 $(8.1 \pm 8.8 \%)$. Consequently, blastocyst yield $(17 \%$ of total oocytes cultured) was highest when oocytes were matured in medium containing higher FSH concentration and antioxidants. The results of this study demonstrate that meiotic and developmental competences are inherent to the immature cat oocyte collected during the non-breeding season. However, appropriate mechanisms (perhaps seasonal variation in $\mathrm{FSH}$ receptors or lack of antioxidant capacity of the cumulus-oocyte complex) are inadequate during this period of gonadal quiescence. Regardless, this compromised oocyte function during the non-breeding season can be overridden by altering in vitro culture conditions to include supplemental FSH and antioxidant.

\section{Introduction}

In domestic cats, in vitro maturation (IVM) studies of intraovarian oocytes have been conducted since 1989 (Johnston et al., 1989). The success of various IVM conditions has been based on nuclear maturation and successful embryo development after IVF (Johnston et al., 1989; Schramm and Bavister, 1995; Wolfe and Wildt, 1996; Spindler and Wildt, 1999; Karja et al., 2002a), intracytoplasmic sperm injection (Gomez et al., 2000; Bogliolo et al., 2001) and nuclear transfer (Skrzyszowska et al., 2002; Gomez et al., 2003; Kitiyanant et al., 2003), including the production of live offspring after embryo transfer (Pope et al., 1997, 2003). In addition, it is well established that the use of strict selection criteria for freshly collected oocytes assists in ensuring higher rates of subsequent IVM and IVF success (Wolfe and Wildt, 1996; Wood and Wildt, 1997a). It is clear and unsurprising that there are vast differences in the quality

Email: comizzolip@nzp.si.edu of oocytes recovered from ovarian tissue (Wood and Wildt, 1997a), which no doubt explains some of the variation in success of IVM across laboratories. Under optimal culture conditions and using grade I oocytes, 59-80\% of immature oocytes, on average, achieve nuclear maturation (Wolfe and Wildt, 1996; Spindler and Wildt, 1999; Gomez et al., 2000; Bogliolo et al., 2001; Otoi et al., 2001). When inseminated with conspecific spermatozoa, $45-50 \%$ of cultured oocytes are fertilized and develop in vitro to the blastocyst stage (Wolfe and Wildt, 1996; Wood and Wildt, 1997a; Spindler and Wildt, 1999; Freistedt et al., 2001; Karja et al., 2002a).

Spindler and Wildt (1999) first reported the marked effect of season on IVM success in cat oocytes. When oocytes were recovered from cat ovaries during the traditional non-breeding season in North America (from July through November), the incidence of nuclear maturation was approximately $20 \%$ and no embryos developed to the blastocyst stage after fertilization. Other studies have confirmed this effect associated with quiescent ovarian 
activity and reduced follicular growth, including studies in other geographic regions and at times of the year that differ from the North American breeding season (Freistedt et al., 2001). FSH is known to be an important supplement for IVM success when using oocytes collected during the breeding season (Johnston et al., 1989; Schramm and Bavister, 1995; Wood et al., 1995). For this reason, Spindler and Wildt (1999) speculated that either lower circulating FSH concentrations or fewer FSH receptors may be contributing to reduced IVM efficiency during the non-breeding season, possibly by adversely affecting oocyte quality. It remains unclear whether the poor nuclear maturation observed during the seasonal quiescent period of the cat is linked to a poor meiotic competence, to a failure to meet a threshold concentration of FSH to induce nuclear maturation, or to both factors.

As FSH receptors are located on cumulus cells, the induction of nuclear maturation must be mediated by these cells, which coincidentally also play a key role in cytoplasmic maturation (Shimada et al., 2002; Tanghe et al., 2002; Webb et al., 2002). Cytoplasmic maturation is generally considered to be the ability of an oocyte to support monospermic fertilization, pronuclear formation and early embryo development (Mermillod et al., 1999; Tanghe et al., 2002). A major cytoplasmic factor regulating sperm decondensation and chromatin remodelling is the reduced form of glutathione $(\mathrm{GSH})$ (de Matos et al., 1997). As a result of an increase in oocyte GSH content, the cumulus cells maintain the redox state while simultaneously protecting the oocyte against oxidative stress (de Matos et al., 1997; Sutovsky and Schatten, 1997). Furthermore, high GSH content in the oocyte is also required for supporting successful embryo development in cattle (de Matos et al., 1997; de Matos and Furnus, 2000). It is also known that supplementing pig oocytes during IVM with cysteine, a precursor of GSH synthesis, enhances cytoplasmic maturation (Yoshida et al., 1993; Abeydeera et al., 1999). Likewise, in rats and mice another extracellular antioxidant, ascorbic acid, protects cumulus cells against apoptosis and improves maturation (Behrman et al., 1996; Takami et al., 1999; Eppig et al., 2000). Acquisition of oocyte competence may be lost because of oxidative stress during IVM. However, the impact of antioxidants on IVM during the non-breeding season in carnivore species, including the domestic cat, is unknown.

The aim of the present study was to determine whether the poor nuclear and cytoplasmic maturation observed during the non-breeding season in the cat is related to decreased sensitivity to FSH and increased oxidative stress. This possibility was examined by characterizing the influence of supplemental FSH (at different concentrations) and antioxidants (ascorbic acid or cysteine) on in vitro nuclear and cytoplasmic maturation of intraovarian cat oocytes recovered during the non-breeding season.

\section{Materials and Methods}

\section{Oocyte collection and IVM}

Ovaries from the adult domestic cat (Felis catus) were collected during the non-breeding season (July to November) from local veterinary clinics and transported in PBS at $4^{\circ} \mathrm{C}$ to the laboratory within $6 \mathrm{~h}$ of ovariectomy. Immature oocytes were then recovered by slicing the ovaries with a scalpel blade in Hepes-buffered minimum essential medium (H-MEM; Gibco Laboratories, Grand Island, NY) supplemented with $1.0 \mathrm{mmol}$ pyruvate $\mathrm{I}^{-1}$, $2.0 \mathrm{mmol}$ L-glutamine $\mathrm{I}^{-1}, 100.0$ iu penicillin $\mathrm{ml}^{-1}$, $100.0 \mathrm{mg}$ streptomycin ml $\mathrm{m}^{-1}$ and $4.0 \mathrm{mg} \mathrm{BSA} \mathrm{m}^{-1}$ (Sigma Chemical Co, St Louis, MO). Only grade I immature oocytes (with homogeneous dark cytoplasm, surrounded by several layers of compacted cumulus) (Wood and Wildt, 1997a) were used. These oocytes were selected and pooled before they were cultured in different IVM media for $32 \mathrm{~h}$ in $50 \mu \mathrm{l}$ microdrops (10 oocytes per microdrop) under mineral oil $\left(38.5^{\circ} \mathrm{C}\right.$ in air with $5 \% \mathrm{CO}_{2}$ ).

IVM control medium (designated IVM1) was used in our laboratory (Wolfe and Wildt, 1996; Spindler and Wildt, 1999) and comprised MEM (Gibco) supplemented with $1.0 \mathrm{mmol}$ L-glutamine $\mathrm{I}^{-1}, 1.0 \mathrm{mmol}$ pyruvate $\mathrm{I}^{-1}$, 100.0 iu penicillin $\mathrm{ml}^{-1}, 100.0 \mathrm{mg}$ streptomycin $\mathrm{ml}^{-1}$, $4.0 \mathrm{mg} \mathrm{BSA} \mathrm{ml}{ }^{-1}, 1.0 \mu \mathrm{g} \mathrm{FSH} \mathrm{ml}{ }^{-1}$ (1.64 iu ml ${ }^{-1}$; NIDDK-ovine FSH-18; National Hormone and Pituitary Program, Rockville, MD), $1.0 \mu \mathrm{g} \mathrm{LH} \mathrm{ml}{ }^{-1}$ (1.06 iu ml ${ }^{-1}$; NIDDK-oLH-25; National Hormone and Pituitary Program) and $1.0 \mu \mathrm{g}$ oestradiol $\mathrm{ml}^{-1}$ (Sigma).

In Expt 1, oocytes were cultured in IVM1 supplemented with different FSH concentrations: 1 (control), 5, 10 or $15 \mu \mathrm{g} \mathrm{ml}^{-1}$. After $32 \mathrm{~h}$ of culture, oocytes were fixed in ethanol overnight at room temperature and stained with $10 \mu \mathrm{g}$ Hoechst $33342 \mathrm{ml}^{-1}$ (Sigma) (Comizzoli et al., 2001). The meiotic stage of the oocytes was assessed by epifluorescence microscopy (Olympus BX 41, Olympus Corporation, Melville, NY) (Johnston et al., 1989; Wood et al., 1995; Wolfe and Wildt, 1996; Spindler and Wildt, 1999).

The results of Expt 1 were used to design the composition of the IVM media used in Expts 2 and 3. For these studies, oocytes were cultured in IVM1 supplemented with either $10.0 \mu \mathrm{g} \mathrm{FSH} \mathrm{ml}{ }^{-1}(\mathrm{FSH}+), 0.5 \mathrm{mmol}$ ascorbic acid $\mathrm{I}^{-1}$ (AS; Sigma), $0.13 \mathrm{mmol}$ cysteine $\mathrm{I}^{-1}$

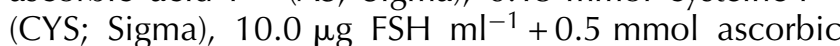

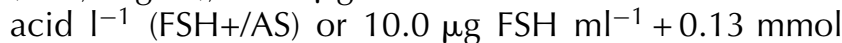
cysteine $\mathrm{I}^{-1}(\mathrm{FSH}+\mathrm{CYS})$. The dosage of the two antioxidants was based on previous studies in pig (Abeydeera et al., 1999) and mouse oocytes (Eppig et al., 2000).

\section{In vitro fertilization and development}

IVF was performed in Expts 2 and 3 using a standard protocol originally developed in our laboratory for oocytes matured in vivo (Johnston et al., 1991a) and later 
for oocytes matured in vitro (Wood et al., 1995). The most recent description of the protocol has been provided by Spindler and Wildt (1999). Briefly, frozen-thawed motile spermatozoa from a single sperm donor were selected by swim-up processing (Goodrowe et al., 1988) in Ham's F-10 medium (Irvine Scientific, Santa Ana, CA) supplemented with $25 \mathrm{mmol}$ Hepes $\mathrm{I}^{-1}, 1 \mathrm{mmol}$ pyruvate $\mathrm{I}^{-1}, 2 \mathrm{mmol}$ glutamine $\mathrm{I}^{-1}, 100$ iu penicillin $\mathrm{ml}^{-1}, 100 \mathrm{mg}$ streptomycin $\mathrm{ml}^{-1}$ and $5 \%(\mathrm{v} / \mathrm{v})$ fetal calf serum (complete Ham's medium with Hepes). Oocytes were inseminated with $5 \times 10^{5}$ motile spermatozoa $\mathrm{ml}^{-1}$ in $50 \mu \mathrm{l}$ microdrops of complete Ham's medium without Hepes under equilibrated mineral oil at $38.5^{\circ} \mathrm{C}$ in air with $5 \% \mathrm{CO}_{2}$. Some of the oocytes $(n=12$ per IVM condition) were incubated without spermatozoa to assess the incidence of parthenogenetic activation. At $16 \mathrm{~h}$ after insemination, cumulus cells were removed by vortexing at maximum setting (Vortex-Genie, Scientific Industries, Bohemia, NY) for 2 min. For Expt 2, presumptive zygotes were fixed and stained as described by Comizzoli et al. (2001) to assess pronuclear formation. Pronucleus morphology was recorded according to its size and localization within the cytoplasm (Hewitson et al., 2000). For Expt 3, presumptive zygotes were cultured in vitro for 7 days in complete Ham's $\mathrm{F}-10\left(38.5^{\circ} \mathrm{C}\right.$ in air with $5 \%$ $\mathrm{CO}_{2}$ ). In vitro development was observed on day 6 and again on day 7 (day 0 corresponding to the day after the in vitro insemination). Embryos were then fixed and stained as described by Comizzoli et al. (2001) to determine the developmental stage and number of blastomeres.

\section{Experimental design and statistical analysis}

Grade I immature oocytes from different ovaries were pooled before random and equal distribution across different IVM conditions. In Expt 1, incidence of nuclear maturation was defined as the number of oocytes at the telophase I or the metaphase II stage relative to the total number of oocytes cultured in vitro. Oocytes that arrested at the germinal vesicle breakdown (GVBD) stage or that only progressed to the metaphase I stage were considered immature (Wolfe and Wildt, 1996; Spindler and Wildt, 1999). Oocytes with fragmented cytoplasm or without chromatin were considered degenerated. In Expt 2, oocytes were considered fertilized when two pronuclei were present in the cytoplasm. The number of unfertilized oocytes in metaphase II was also assessed in this experiment to determine the incidence of nuclear maturation at the time of in vitro insemination. In Expt 3, the percentage of cleaved embryos and blastocyst yield were calculated relative to the total number of oocytes cultured in vitro. Developmental competence was defined as the number of blastocysts produced relative to the total number of cleaved embryos. All experiments were replicated three or four times on different days with different batches of oocytes. Average values were ex-

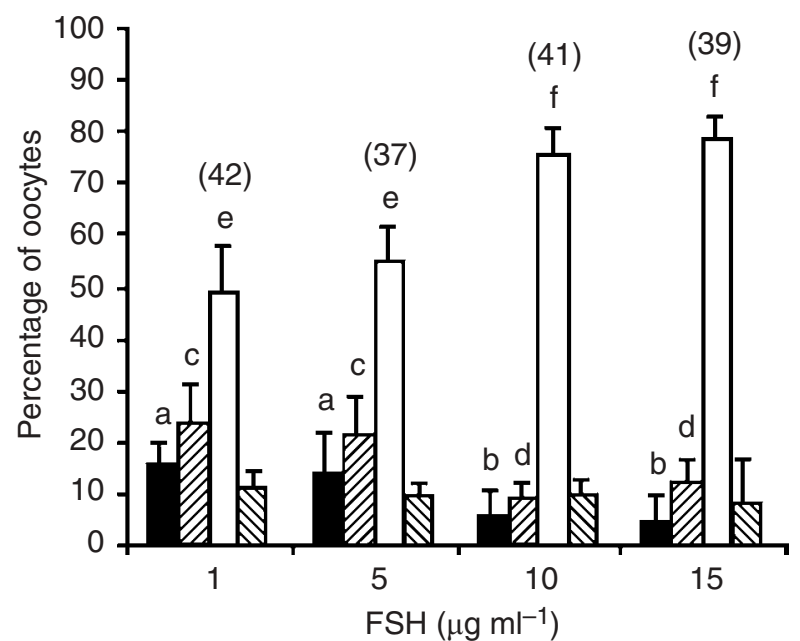

Fig. 1. Percentage of grade I cat oocytes at different nuclear status

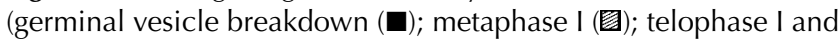
metaphase II ( $\square$ ); degenerated (固)) after in vitro maturation in conventional IVM medium (IVM1) plus different FSH concentrations (three replicates per condition; values are mean $\pm \mathrm{SD}$; values above bars represent total number of oocytes per treatment). ${ }^{a-f}$ Among FSH concentrations, bars with different superscripts are significantly different $(P<0.05)$.

pressed as mean \pm SD. Percentage data were transformed using arcsin transformation before analysis. Comparison between IVM condition and among replicates were analysed by ANOVA and Tukey's multiple comparison testing (SigmaStat, SPSS, Chicago, IL).

\section{Results}

Ovarian activity and oocyte recovery during the non-breeding season

Of the 414 ovaries collected from July through November for this study, none contained corpora lutea or corpora haemorrhagica. Furthermore, all antral follicles observed were $<1 \mathrm{~mm}$ in diameter. The mean number of grade I oocytes recovered per ovary was $2.7 \pm 0.7$.

\section{Effects of FSH on oocyte nuclear maturation}

In this experiment designed to assess the impact of FSH concentration, an examination of oocytes before fixation revealed no apparent gross influence of gonadotrophin concentration on expansion of the surrounding cumulus mass. However, in the presence of 10 or $15 \mu \mathrm{g}$ $\mathrm{FSH} \mathrm{ml} \mathrm{m}^{-1}$, the percentage of oocytes in telophase I or metaphase II was significantly higher $(P<0.05)$, and the percentage of oocytes undergoing GVBD and reaching metaphase I was significantly lower $(P<0.05)$ compared with oocytes in the presence of 1 or $5 \mu \mathrm{g} \mathrm{FSH} \mathrm{ml} \mathrm{m}^{-1}$ (Fig. 1). The incidence of oocyte degeneration was not significantly different among treatments. As nuclear maturation was significantly enhanced in the presence of 


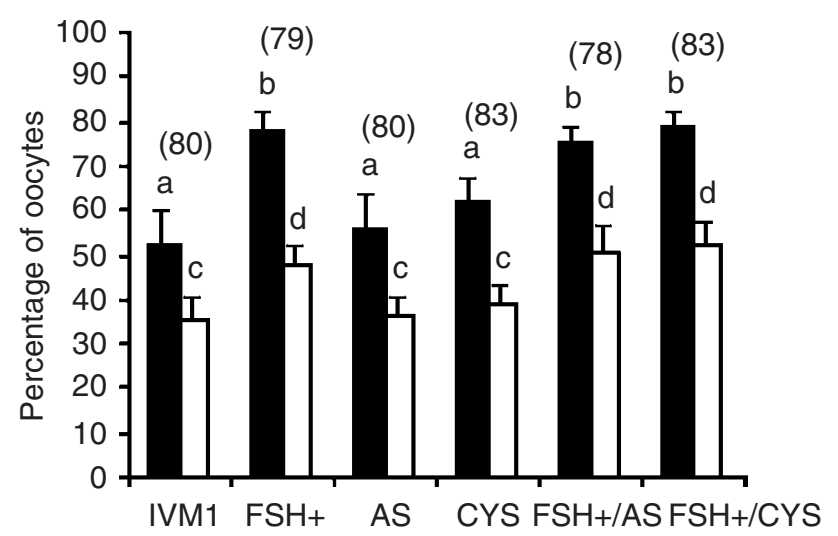

Fig. 2. Percentage of grade I cat oocytes reaching metaphase II (ם) and undergoing fertilization ( $\square$ ) (16 h after insemination) after in vitro maturation (IVM) in different conditions (IVM1: conventional in vitro maturation medium; FSH+: IVM1 with FSH; AS: IVM1 with ascorbic acid; CYS: IVM1 with cysteine; FSH+/AS: IVM1 with FSH and ascorbic acid; FSH+/CYS: IVM1 with FSH and cysteine) (four replicates per condition; values are mean $\pm S D$; numbers above bars represent total number of oocytes per treatment). ${ }^{a-d}$ Among IVM conditions, bars with different superscripts are significantly different $(P<0.05)$.

$10 \mu \mathrm{g} \mathrm{FSH} \mathrm{ml} \mathrm{m}^{-1}$ and was not further increased by $15 \mu \mathrm{g}$ $\mathrm{FSH} \mathrm{ml} \mathrm{m}^{-1}$, subsequent experiments were carried out in the presence of $10 \mu \mathrm{g} \mathrm{FSH} \mathrm{m}{ }^{-1}$.

Effect of higher FSH concentration in the presence or absence of antioxidant on oocyte nuclear maturation and fertilization

Expt 2 replicated the findings of Expt 1 in that nuclear maturation was positively influenced $(P<0.05)$ by the higher FSH concentration (FSH+ versus IVM1; Fig. 2). This improved maturation was also noted in the presence of $10 \mu \mathrm{g} \mathrm{FSH} \mathrm{ml}{ }^{-1}$ combined with ascorbic acid ( $\mathrm{FSH}+$ / AS) or cysteine ( $\mathrm{FSH}+/ \mathrm{CYS}$ ) (Fig. 2). As might be expected, the percentages of oocytes in GVBD and at metaphase I were significantly lower $(P<0.05)$ in all groups with the $10 \mu \mathrm{g} \mathrm{FSH} \mathrm{ml}{ }^{-1}$ (data not shown). The addition of antioxidant to the IVM medium alone (AS or CYS) or in combination with the higher FSH concentration (FSH+/AS, FSH+/CYS) had no significant accentuating effect on nuclear maturation, and the incidence of degeneration (approximately $10 \%$ ) was not significantly different among treatments. The percentage of fertilized oocytes was significantly higher $(P<0.05)$ after IVM in the presence of all the higher $\mathrm{FSH}$ concentration treatments $(\mathrm{FSH}+, \mathrm{FSH}+\mathrm{AS}, \mathrm{FSH}+\mathrm{CYS})$ compared with the other IVM conditions (IVM1, AS, CYS).

The number of fertilized oocytes relative to the number of matured oocytes did not differ significantly $(P>0.05)$ among the five treatments (data not shown) and averaged approximately $66 \%$. No parthenogenetic activation was detected and fertilized oocytes with more
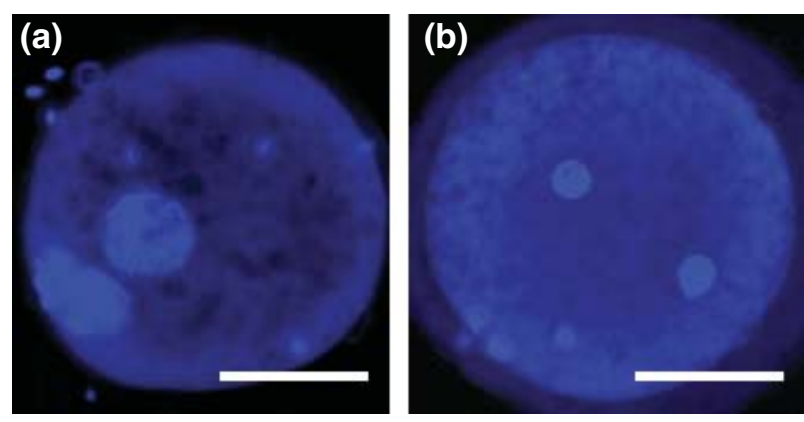

Fig. 3. Pronuclear morphology at $16 \mathrm{~h}$ after insemination after in vitro maturation of grade I cat oocytes in the (a) presence or (b) absence of ascorbic acid or cysteine. Scale bars represent $50 \mu \mathrm{m}$.

than two pronuclei were not observed. At $16 \mathrm{~h}$ after insemination, the proportion of zygotes with two fully developed pronuclei (Fig. 3a) was higher $(P<0.05)$ after IVM in the presence of antioxidant (AS, $66.7 \pm 5.4 \%$; CYS, $66.0 \pm 5.2 \% ; \mathrm{FSH}+/ \mathrm{AS}, 63.5 \pm 3.9 \% ; \mathrm{FSH}+/ \mathrm{CYS}$, $62.8 \pm 5.9 \%)$ compared with IVM1 only $(32.5 \pm 2.1 \%)$ or the higher concentration of $\mathrm{FSH}$ in the absence of antioxidant $(\mathrm{FSH}+, 32.5 \pm 3.8 \%)$. For the last two treatments, pronuclei were generally smaller and more distantly spaced at $16 \mathrm{~h}$ after insemination (Fig. 3b).

Effect of higher FSH concentration in the presence or absence of antioxidant on embryo cleavage, developmental competence and blastocyst yield

In Expt 3, the same proportion of fertilized oocytes progressed to the first cleavage stage regardless of the IVM treatment. Compared with the IVM1 control, the percentage of cleaved embryos was higher $(P<0.05)$ when IVM was performed in the presence of $10 \mu \mathrm{g} \mathrm{FSH}$ $\mathrm{ml}^{-1}$ with or without the antioxidants $(\mathrm{FSH}+, \mathrm{FSH}+/ \mathrm{AS}$, $\mathrm{FSH}+/ \mathrm{CYS}$; Fig. 4). There was no enhancement effect by the presence of either ascorbic acid or cysteine, and neither antioxidant alone promoted cleavage. The percentage of blastocysts relative to the number of cleaved embryos (developmental competence) was always significantly higher $(P<0.05)$ after IVM in the presence of the antioxidants and with or without the higher $\mathrm{FSH}$ concentration (AS, CYS, FSH+/AS, FSH+/CYS; Fig. 4). The presence of higher $\mathrm{FSH}$ concentration and antioxidant during oocyte IVM (FSH+/AS, FSH+/CYS) increased $(P<0.05)$ blastocyst yield (number of blastocysts relative to the total number of oocytes) compared with all other IVM treatments (that is, IVM1, FSH+, AS, CYS; Fig. 4).

The developmental stages of embryos across treatments are shown (Fig. 5). More embryos $(P<0.05)$ developed beyond the 2- to 8-cell stage after IVM in all supplemented media compared with IVM1. Embryo development was mainly arrested at the 816 -cell stage $(P<0.05$; Figs $5,6 b)$ when the original 


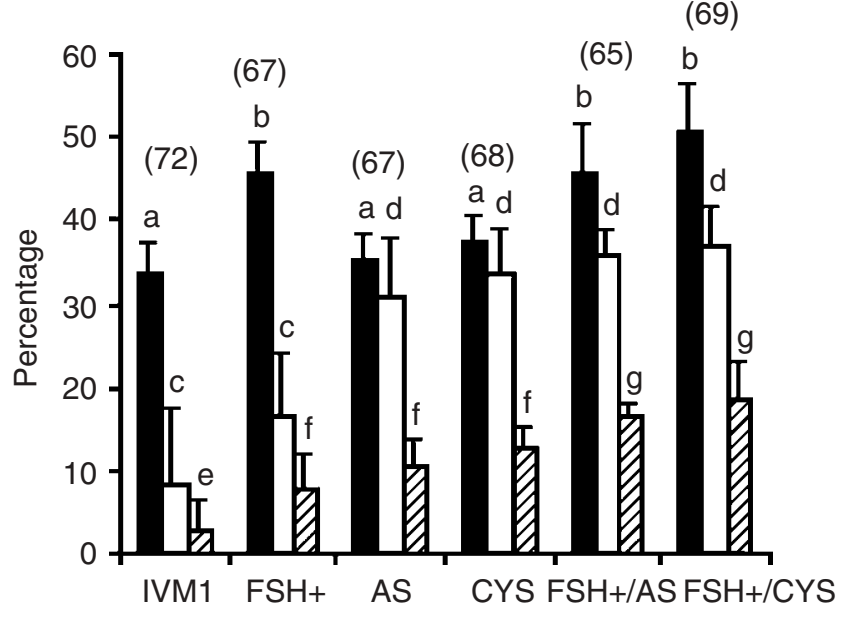

Fig. 4. Percentages of cleaved embryos (ם), percentages of blastocysts relative to number of cleaved embryos ( $\square$, developmental competence) and percentages of blastocysts relative to total number of oocytes (圈, blastocyst yield) on day 7 after in vitro maturation (IVM) in different conditions (IVM1: conventional in vitro maturation medium; FSH+: IVM1 with FSH; AS: IVM1 with ascorbic acid; CYS: IVM1 with cysteine; FSH+/AS: IVM1 with FSH and ascorbic acid; FSH+/CYS: IVM1 with FSH and cysteine) (three replicates per condition, values are mean \pm SD; values above bars represent the total number of oocytes per treatment). ${ }^{a-g}$ Among IVM conditions, bars with different superscripts are significantly different $(P<0.05)$.

(24)

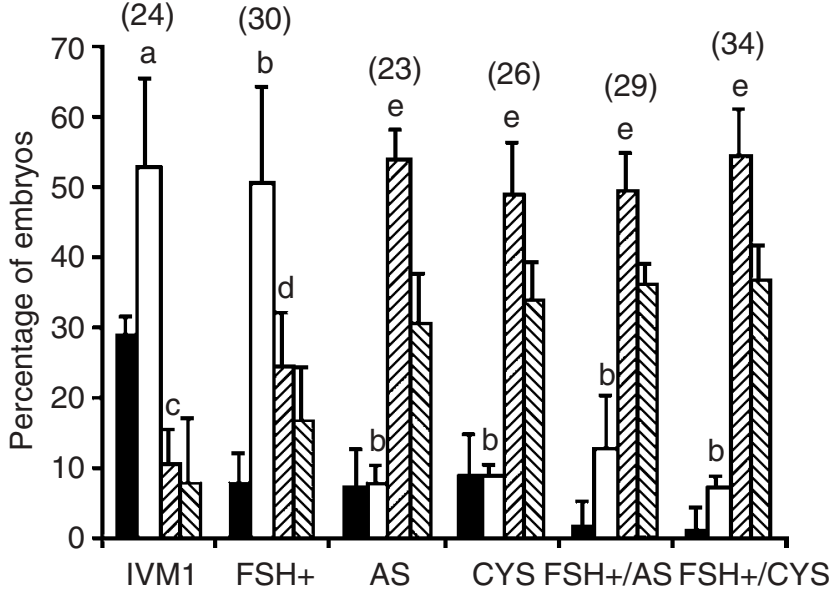

Fig. 5. Proportion of embryos at different stages of development ( $\square$, 2-8 cells; $\square, 8-16$ cells; 图, morulae; 固, blastocysts) on day 7 (three replicates per condition; values are mean $\pm \mathrm{SD}$; values above bars represent the total number of embryos per treatment). ${ }^{\mathrm{a}-\mathrm{e}}$ Among IVM conditions, bars with different superscripts are significantly different $(P<0.05)$. IVM1: conventional in vitro maturation medium; FSH+: IVM1 with FSH; AS: IVM1 with ascorbic acid; CYS: IVM1 with cysteine; FSH+/AS: IVM1 with FSH and ascorbic acid; FSH+/CYS: IVM1 with FSH and cysteine.

oocytes were cultured in IVM1 or supplemented with higher FSH alone. In contrast, the presence of the antioxidant with or without the higher $\mathrm{FSH}$ concentration enhanced $(P<0.05$; Fig. 5$)$ the proportion of resulting
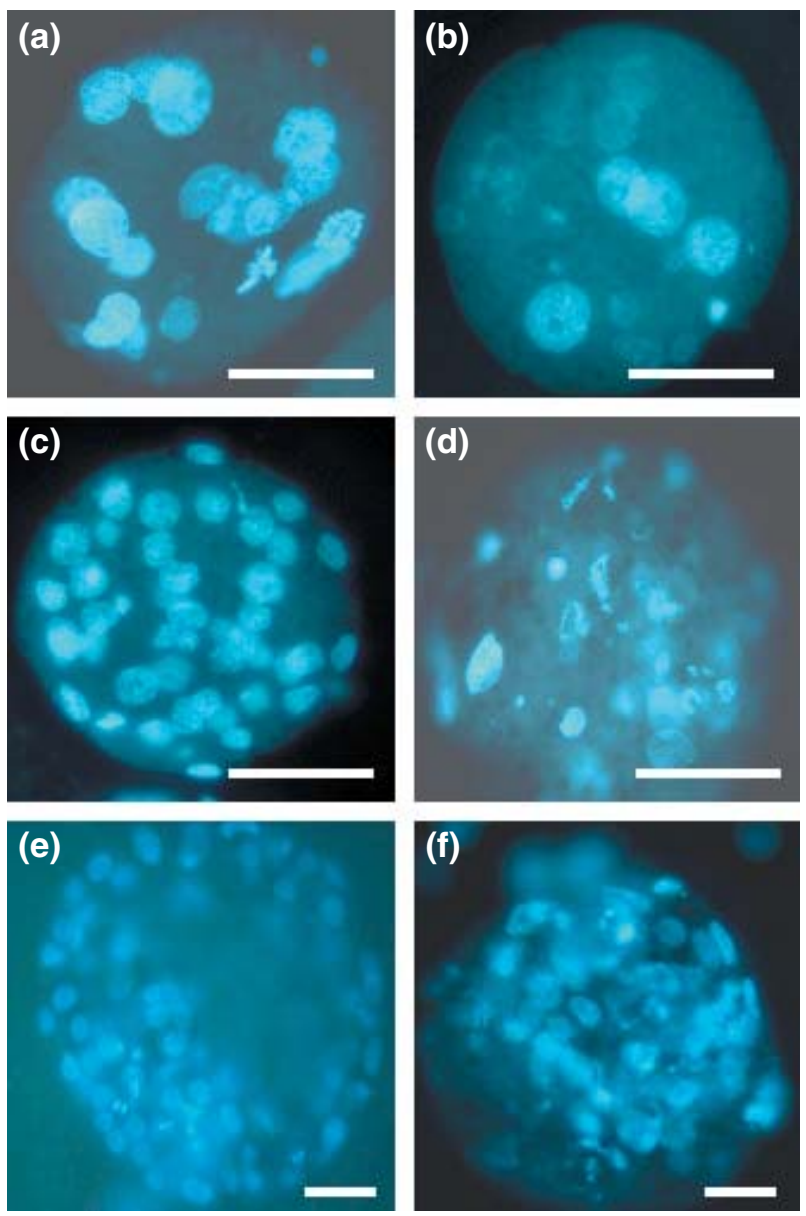

Fig. 6. Morphology of cat embryos after in vitro maturation of grade l oocytes in the $(\mathrm{a}, \mathrm{c}, \mathrm{e})$ presence or $(\mathrm{b}, \mathrm{d}, \mathrm{f})$ absence of ascorbic acid or cysteine. $(a, b) 8-16$-cell stage, $(c, d)$ morula stage and $(e, f)$ blastocyst stage (after 7 days of in vitro development). Scale bars represent $50 \mu \mathrm{m}$.

morulae and blastocysts (Fig. 6c,e). On day 6 of culture in vitro, blastocyst formation was observed only in the four treatments containing antioxidant. The morphological benefits of supplemental ascorbic acid or cysteine are shown (Fig. 6). In addition to more uniform blastomeres and the absence of pycnotic nuclei at different developmental stages, the mean number of cells for blastocysts was higher $(P<0.05)$ after IVM in the presence of antioxidant $(88.4 \pm 10.3$ cells, combined average for AS, CYS, FSH+/AS, FSH+/CYS) compared with the absence of antioxidant (59.6 \pm 8.8 cells, combined average for IVM1 and $\mathrm{FSH}+$ ).

\section{Discussion}

The present study provides important insight into two potential causes of compromised IVM/IVF capacity in intraovarian cat oocytes collected during the traditional non-breeding season. First, it was discovered that the 
conventional IVM medium for this species benefited from a higher FSH concentration that, in turn, increased both nuclear maturation and fertilization success. As there was no difference in the results from using 10 or $15 \mu \mathrm{g} \mathrm{FSH}$ $\mathrm{ml}^{-1}$, there appeared to be a threshold effect after which there was no further advantage of more gonadotrophin in the culture medium. Second, supplementing the IVM medium with the antioxidants ascorbic acid or cysteine had a particularly beneficial impact on advanced embryo development in vitro, especially from the 8-16 cell to the blastocyst stage. Both of these findings were significant in helping to speculate about arrested or dysfunctional mechanisms in oocytes during intervals of reproductive acyclicity in this species. Finally, the results of the present study demonstrate that simple supplements to conventional IVM conditions circumvented the maturational and developmental compromise that, in turn, resulted in healthy embryo numbers near those reported in studies conducted during the breeding season (Wolfe and Wildt, 1996; Spindler and Wildt, 1999; Freistedt et al., 2001; Karja et al., 2002a).

More specifically, the percentages of cat oocytes reaching metaphase II in the control group of the present study were comparable using the same IVM medium in our laboratory and $1 \mu \mathrm{g} \mathrm{FSH} \mathrm{ml} l^{-1}$ (previous study, breeding season) (Spindler and Wildt, 1999) versus $10 \mu \mathrm{g}$ $\mathrm{FSH} \mathrm{ml}^{-1}$ (the present study, non-breeding season). The findings of the present study were similar to percentages of oocytes reaching metaphase II or undergoing degeneration after IVM using oocytes collected during the breeding season by other laboratories (Pope et al., 1998; Gomez et al., 2000; Bogliolo et al., 2001; Otoi et al., 2001; Karja et al., 2002a). Culturing in the presence of higher concentrations of $\mathrm{FSH}$ also promoted meiotic resumption from both the GVBD stage and the metaphase I stage. Although increased FSH concentration in the culture medium has been shown to enhance nuclear maturation in bovine oocytes (Izadyar et al., 1998; Choi et al., 2001), the present study was the first to report that supplementation with high concentrations of gonadotrophins enhanced oocyte function in vitro during a seasonally related interval of compromised gamete function. It was apparent that immature cat oocytes recovered during the non-breeding season had full meiotic competence, but required supplemental FSH to advance the maturation process. Although circannual FSH patterns have not been studied in the cat, it is well known that GnRH and FSH secretion patterns decrease in other seasonally breeding mammals (Lehman et al., 1997). In addition, treating the squirrel monkey (Yeoman et al., 1994) or ewe (Stenbak et al., 2001) (the whole animal) with FSH during seasonal periods of ovarian inactivity is known to improve oocyte nuclear maturation and developmental competence. Particularly interesting from the present study is that FSH priming in cats can be delayed until the oocytes are placed in culture. The mechanism by which higher FSH exerts an effect in culture remains unknown, although a plausible explanation could be a circumvention of a naturally depressed number of functional FSH receptors. Supplementing FSH may largely allow targeting all available receptors to facilitate communication between the somatic cells and the oocyte itself (Eppig et al., 2000; Tanghe et al., 2002; Webb et al., 2002). Concentrations of FSH are difficult to compare among IVM studies in the domestic cat from 0.02 iu bovine FSH ml-1 (Freistiedt et al., 2001) to $1.0 \mu \mathrm{g} \mathrm{FSH} \mathrm{ml}{ }^{-1}$ (Schramm and Bavister, 1995) because of different purity and origin of the hormones. However, the highly purified FSH used in the present study did not contain any contaminants that might have influenced the nuclear maturation and the cumulus expansion.

Although the higher $\mathrm{FSH}$ concentration promoted fertilization success similar to that measured during the breeding season (Spindler and Wildt, 1999; Freistedt et al., 2001; Karja et al., 2002a), the addition of only ascorbic acid or cysteine to the IVM medium failed to enhance either nuclear maturation or fertilization. The latter observation is consistent with previous reports for pig (Yoshida et al., 1993; Tatemoto et al., 2001), rat (Takami et al., 1999) and goat oocytes (Mayor et al., 2001). However, these antioxidants profoundly influenced the morphology of cat pronuclei at $16 \mathrm{~h}$ after insemination, indicative of a more rapid and improved chromatin remodelling which was probably due to enhanced cytoplasmic maturation (Yoshida et al., 1993; Collas, 1998; Tatemoto et al., 2001).

As more oocytes exposed to higher FSH concentration underwent successful maturation in culture in the present study, more fertilized and cleaved. As others have already asserted (Schramm and Bavister, 1995; Wood et al., 1995), the benefits of this gonadotrophin are exerted via its impact on nuclear maturation rather than improved fertilization and developmental competence. After 7 days in culture, the proportion of embryos developing beyond the 2- to 8-cell stage was increased markedly in all supplemented media. This finding was not influenced by parthenogenetic activation. Although IVM culture supplementation influenced nuclear and cytoplasmic maturation, the percentage of blastocysts eventually developing was $10 \%$ less than that reported in comparable studies conducted during the breeding season (Wolfe and Wildt, 1996; Spindler and Wildt, 1999; Freistedt et al., 2001; Karja et al., 2002a). Nonetheless, blastocyst quality in terms of developmental pace in vitro, total number and uniformity of blastomeres produced was better in the presence, rather than the absence, of either antioxidant. Furthermore, these traits were similar to those reported for IVM/IVF oocytes collected from cats during the breeding season (Spindler and Wildt, 2002; Karja et al., 2002b).

The benefits of adding ascorbic acid to IVM culture conditions have been reported for pigs (Tatemoto et al., 2001). Extracellular cysteine supplementation too has 
been shown to enhance embryo development in bovine (de Matos et al., 1997; de Matos and Furnus, 2000) and pig (Yoshida et al., 1993) oocytes. It is possible that the maternal-zygotic transition and the onset of embryonic transcription (which occurs at the 5- to 8-cell stage in cats; Hoffert et al., 1997) was improved in the presence of antioxidant because we observed more embryos developed beyond the 8-16-cell stage when IVM medium contained ascorbic acid or cysteine. Clearly, the presence of these antioxidants promoted developmental competence. As ascorbic acid and cysteine provided similar beneficial effects on early chromatin remodelling (either by protecting cumulus cells via the former or improving GSH synthesis via the latter), it appeared that these early stage, immature oocytes were particularly sensitive to oxidative stress during the nonbreeding season. The antioxidant capacity of the oocyte could be decreased during this period because of a depletion of GSH synthesis or an altered metabolism (Sutovsky and Schatten, 1997; Spindler et al., 2000). It is highly likely that the beneficial effect observed in this study was induced by a positive signal, which then was transferred from cumulus cells to the oocyte (Behrman et al., 1996) without any interaction with the FSH concentration. Regardless, although supplemental antioxidant seemed to ensure improved chromatin remodelling (as demonstrated by excellent pronuclear morphology after insemination) and maternal-zygotic transition, embryos arrested at the morula-blastocyst transition. This block is not directly related to IVM conditions or the onset of embryonic transcription, but rather to inadequate culture conditions during the early stages of embryo development (Schramm and Bavister, 1995; Hoffert et al., 1997).

The present study has demonstrated that cat follicles during the non-breeding season (most of which are $<1 \mathrm{~mm}$ in diameter) contain oocytes that already have meiotic and developmental competence. Furthermore, despite an impressive amount of follicular atresia (approximately 65\%) occurring at any given time in this species (Wood et al., 1997b), a significant number of viable oocytes are recoverable and can undergo embryogenesis by altering culture conditions. Nuclear and cytoplasmic maturation benefit from supplemental $\mathrm{FSH}$, and developmental competence is improved by the antioxidants ascorbic acid or cysteine. The exact mechanism responsible for this phenomenon is currently under investigation in our laboratory. Specifically, the seasonal changes in FSH receptor concentration and functionality as well as modulation of GSH contents in the cumulus-oocyte complex are being investigated.

Finally, these studies have application to our parallel efforts to manage small populations of endangered felid species. Some basic studies in these species have been carried out in our laboratory (Johnston et al., 1991b) as well as the laboratories of others (Jewgenow et al., 1997). Wild felid species are especially prone to seasonal breeding patterns to ensure the production of young at times of the year most conducive to offspring survival (Wildt et al., 1998). Thus, the findings of the present study will also be used to continue comparative assessments of reproductive mechanisms among species of the Felidae as well as hopefully to improve IVM-IVF results in zoohoused, valuable specimens that die unexpectedly during seasonal anoestrus.

This study was supported by a fellowship to P. Comizzoli from the Smithsonian Institution Scholarly Studies Program, and the National Institutes of Health to B. S. Pukazhenthi (KO1 RR00135). The authors thank M. Cranfield and B. Whitaker (Maryland Line Animal Rescue) and D. Thornburg (Petworth Animal Hospital) for providing domestic cat ovaries. The authors also thank R. E. Spindler for valuable scientific advice.

\section{References}

Abeydeera LR, Wang WH, Cantley TC, Prather RS and Day BN (1999) Glutathione content and embryo development after in vitro fertilisation of pig oocytes matured in the presence of a thiol compound and various concentrations of cysteine Zygote 7 203-210

Behrman HR, Preston SL, Aten RF, Rinaudo P and Zreik TG (1996) Hormone induction of ascorbic acid transport in immature granulosa cells Endocrinology 137 4316-4321

Bogliolo L, Leoni G, Ledda S, Naitana S, Zedda M, Carluccio A and Pau S (2001) Intracytoplasmic sperm injection of in vitro matured oocytes of domestic cats with frozen-thawed epididymal spermatozoa Theriogenology 56 955-967

Choi YH, Carnevale EM, Seidel GE, Jr and Squire EL (2001) Effects of gonadotropins on bovine oocytes matured in TCM-199 Theriogenology 56 661-670

Collas P (1998) Cytoplasmic control of nuclear assembly Reproduction, Fertility and Development 10 581-592

Comizzoli P, Mermillod P, Cognie Y, Chai N, Legendre $\mathbf{X}$ and Mauget $\mathbf{R}$ (2001) Successful in vitro production of embryos in the red deer (Cervus elaphus) and the sika deer (Cervus nippon) Theriogenology 55 649-659

de Matos DG and Furnus CC (2000) The importance of having high glutathione $(\mathrm{GSH})$ level after bovine in vitro maturation on embryo development effect of beta-mercaptoethanol, cysteine and cystine Theriogenology 53 761-771

de Matos DG, Furnus CC and Moses DF (1997) Glutathione synthesis during in vitro maturation of bovine oocytes: role of cumulus cells Biology of Reproduction 57 1420-1425

Eppig JJ, Hosoe M, O'Brien MJ, Pendola FM, Requena A and Watanabe $S$ (2000) Conditions that affect acquisition of developmental competence by mouse oocytes in vitro: FSH, insulin, glucose and ascorbic acid Molecular and Cellular Endocrinology 163 109-116

Freistedt P, Stojkovic M and Wolf E (2001) Efficient in vitro production of cat embryos in modified synthetic oviduct fluid medium: effects of season and ovarian status Biology of Reproduction 65 9-13

Gomez MC, Pope CE, Harris R, Davis A, Mikota S and Dresser BL (2000) Births of kittens produced by intracytoplasmic sperm injection of domestic cat oocytes matured in vitro. Reproduction, Fertility and Development 12 423-433

Gomez MC, Jenkins JA, Giraldo A, Harris RF, King A, Dresser BL and Pope CE (2003) Nuclear transfer of synchronized african wild cat somatic cells into enucleated domestic cat oocytes Biology of Reproduction 69 1032-1041

Goodrowe KL, Wall RJ, O'Brien SJ, Schmidt PM and Wildt DE (1988) Developmental competence of domestic cat follicular oocytes after fertilization in vitro. Biology of Reproduction 39 355-372

Hewitson L, Simerly C and Schatten G (2000) Cytoskeletal aspects of assisted fertilization Seminars in Reproductive Medicine 18 151-159 
Hoffert KA, Anderson GB, Wildt DE and Roth TL (1997) Transition from maternal to embryonic control of development in IVM/IVF domestic cat embryos Molecular Reproduction and Development 48 208-215

Izadyar F, Zeinstra E and Bevers MM (1998) Follicle-stimulating hormone and growth hormone act differently on nuclear maturation while both enhance developmental competence of in vitro matured bovine oocytes Molecular Reproduction and Development 51 339-345

Jewgenow K, Blottner S, Lengwinat T and Meyer HH (1997) New methods for gamete rescue from gonads of non-domestic felids Journal of Reproduction and Fertility Supplement 51 33-39

Johnston LA, O'Brien SJ and Wildt DE (1989) In vitro maturation and fertilization of domestic cat follicular oocytes Gamete Research 24 343356

Johnston LA, Donoghue AM, O'Brien SJ and Wildt DE (1991a) Culture medium and protein supplementation influence in vitro fertilization and embryo development in the domestic cat Journal of Experimental Zoology 257 350-359

Johnston LA, Donoghue AM, O'Brien SJ and Wildt DE (1991b) Rescue and maturation in vitro of follicular oocytes collected from non-domestic felid species Biology of Reproduction 45 898-906

Karja NW, Otoi T, Murakami M, Fahrudin M and Suzuki T (2002a) In vitro maturation, fertilization and development of domestic cat oocytes recovered from ovaries collected at three stages of the reproductive cycle Theriogenology 57 2289-2298

Karja NW, Otoi T, Murakami M, Yuge M, Fahrudin M and Suzuki T (2002b) Effect of protein supplementation on development to the hatching and hatched blastocyst stages of cat IVF embryos Reproduction, Fertility and Development 14 291-296

Kitiyanant Y, Saikhun J and Pavasuthipaisit K (2003) Somatic cell nuclear transfer in domestic cat oocytes treated with IGF-I for in vitro maturation Theriogenology 59 1775-1786

Lehman MN, Goodman RL, Karsch FJ, Jackson GL, Berriman SJ and Jansen HT (1997) The GnRH system of seasonal breeders: anatomy and plasticity Brain Research Bulletin 44 445-457

Mayor P, Lopez-Bejar M, Rodriguez-Gonzalez E and Paramio MT (2001) Effects of the addition of glutathione during maturation on in vitro fertilisation of prepubertal goat oocytes Zygote 9 323-330

Mermillod P, Oussaid B and Cognie Y (1999) Aspects of follicular and oocyte maturation that affect the developmental potential of embryos Journal of Reproduction and Fertility Supplement 54 449-460

Otoi T, Murakami M, Ooka A, Karja NW and Suzuki T (2001) Effects of size and storage temperature on meiotic competence of domestic cat oocytes Veterinary Record 148 116-118

Pope CE, McRae MA, Plair BL, Keller GL and Dresser BL (1997) In vitro and in vivo development of embryos produced by in vitro maturation and in vitro fertilization of cat oocytes Journal of Reproduction and Fertility Supplement 51 69-82

Pope CE, Johnson CA, McRae MA, Keller GL and Dresser BL (1998) Development of embryos produced by intracytoplasmic sperm injection of cat oocytes Animal Reproduction Science 53 221-236

Pope CE, Gomez MC, King AL, Harris RF and Dresser BL (2003) Embryos produced in vitro after recovery of oocytes from cat ovaries stored at $4^{\circ} \mathrm{C}$ for 24 to 28 hours retain the competence to develop into live kittens after transfer to recipient Theriogenology 59308 (Abstract 308)

Schramm RD and Bavister BD (1995) Effects of gonadotrophins, growth hormone and prolactin on developmental competence of domestic cat oocytes matured in vitro. Reproduction, Fertility and Development 7 1061-1066

Shimada M, Kawano N and Terada T (2002) Delay of nuclear maturation and reduction in developmental competence of pig oocytes after mineral oil overlay of in vitro maturation media Reproduction 124 557-564

Skrzyszowska M, Katska L, Rynska B, Kania G, Smorag Z and Pienkowski M (2002) In vitro developmental competence of domestic cat embryos after somatic cloning: a preliminary report Theriogenology 58 1615-1621
Spindler RE and Wildt DE (1999) Circannual variations in intraovarian oocyte but not epididymal sperm quality in the domestic cat Biology of Reproduction 61 188-194

Spindler RE and Wildt DE (2002) Quality and age of companion felid embryos modulate enhanced development by group culture Biology of Reproduction 66 167-173

Spindler RE, Pukazhenthi BS and Wildt DE (2000) Oocyte metabolism predicts the development of cat embryos to blastocyst in vitro. Molecular Reproduction and Development 56 163-171

Stenbak TK, Redmer DA, Berginski HR et al. (2001) Effects of follicle stimulating hormone ( $\mathrm{FSH}$ ) on follicular development, oocyte retrieval, and in vitro fertilization (IVF) in ewes during breeding season and seasonal anestrus Theriogenology 56 51-64

Sutovsky P and Schatten G (1997) Depletion of glutathione during bovine oocyte maturation reversibly blocks the decondensation of the male pronucleus and pronuclear apposition during fertilization Biology of Reproduction 56 1503-1512

Takami M, Preston SL, Toyloy VA and Behrman HR (1999) Antioxidants reversibly inhibit the spontaneous resumption of meiosis American Journal of Physiology 276 E684-688

Tanghe S, Van Soom A, Nauwynck H, Coryn M and de Kruif A (2002) Minireview: functions of the cumulus oophorus during oocyte maturation, ovulation, and fertilization Molecular Reproduction and Development 61 414-424

Tatemoto H, Ootaki K, Shigeta K and Muto N (2001) Enhancement of developmental competence after in vitro fertilization of porcine oocytes by treatment with ascorbic acid 2-O-alpha-glucoside during in vitro maturation Biology of Reproduction 65 1800-1806

Webb RJ, Marshall F, Swann K and Carroll J (2002) Follicle-stimulating hormone induces a gap junction-dependent dynamic change in [CAMP] and protein kinase a in mammalian oocytes Developmental Biology 246 441-454

Wildt DE, Brown JL and Swanson WF (1998) Reproduction in cats. In Encyclopedia of Reproduction pp 497-510 Eds E Knobil and JD Neill. Academic Press, New-York

Wolfe BA and Wildt DE (1996) Development to blastocysts of domestic cat oocytes matured and fertilized in vitro after prolonged cold storage Journal of Reproduction and Fertility 106 135-141

Wood TC and Wildt DE (1997) Effect of the quality of the cumulusoocyte complex in the domestic cat on the ability of oocytes to mature, fertilize and develop into blastocysts in vitro. Journal of Reproduction and Fertility 110 355-360

Wood TC, Byers AP, Jennette BE and Wildt DE (1995) Influence of protein and hormone supplementation on in vitro maturation and fertilization of domestic cat eggs Journal of Reproduction and Fertility 104 315-323

Wood TC, Montali RJ and Wildt DE (1997) Follicle-oocyte atresia and temporal taphonomy in cold-stored domestic cat ovaries Molecular Reproduction and Development 46 190-200

Yeoman RR, Helvacioglu A, Williams LE, Aksel S and Abee CR (1994) Restoration of oocyte maturational competency during the nonbreeding season with follicle-stimulating hormone stimulation in squirrel monkeys (Saimiri boliviensis boliviensis) Biology of Reproduction $\mathbf{5 0}$ 329-335

Yoshida M, Ishigaki K, Nagai T, Chikyu M and Pursel VG (1993) Glutathione concentration during maturation and after fertilization in pig oocytes: relevance to the ability of oocytes to form male pronucleus Biology of Reproduction 49 89-94

Received 20 June 2003.

First decision 5 August 2003.

Revised manuscript received 18 August 2003.

Accepted 27 August 2003. 